\title{
Warty-basaloid carcinoma: clinicopathological features of a distinctive penile neoplasm. Report of 45 cases
}

\author{
Alcides Chaux ${ }^{1}$, Pheroze Tamboli ${ }^{2}$, Alberto Ayala ${ }^{2}$, Fernando Soares $^{3}$, Ingrid Rodríguez ${ }^{1}$, \\ José Barreto ${ }^{1}$ and Antonio L Cubilla ${ }^{1}$ \\ ${ }^{1}$ Instituto de Patología e Investigación, Asunción, Paraguay; ${ }^{2}$ Department of Pathology, MD Anderson Cancer \\ Center and the Methodist Hospital, Houston, TX, USA and ${ }^{3}$ Department of Pathology, Hospital do Cancer \\ A.C. Camargo, São Paulo, Brazil
}

\begin{abstract}
Most penile cancers are squamous cell carcinomas, but there are several subtypes with different clinicopathologic, viral, and outcome features. We are presenting 45 cases of a distinctive morphological variant of penile squamous cell carcinoma composed of mixed features of warty and basaloid carcinomas. This tumor was earlier recognized in a recent viral study and showed a high association with human papillomavirus infection. However, clinicopathologic features are not well known. In this multi-institutional study, patients' mean age was 62 years. Most tumors (64\%) invaded multiple anatomical compartments, including glans, coronal sulcus, and, especially, inner foreskin mucosa. Tumor size ranged from 2 to $12 \mathrm{~cm}$ (mean $5.5 \mathrm{~cm}$ ). Three morphological patterns were recognized: (1) the most common, observed in two-thirds of the cases was that of a typical condylomatous tumor on surface and basaloid features in deep infiltrative nests; (2) in $15 \%$ of the cases, there were non-papillomatous invasive carcinoma nests with mixed basaloid and warty features; and (3) unusually, predominantly papillomatous. Invasion of penile erectile tissues was frequent, either corpus spongiosum or cavernosum (47\% each). Tumors limited to lamina propria were rare. Most tumors were of high grade (89\%). Vascular and perineural invasion were found in about one-half and one-quarter of cases, respectively. Associated penile intraepithelial neoplasia was identified in 19 cases and mostly showed basaloid, warty-basaloid, or warty features. Inguinal nodal metastases were found in $\mathbf{1 1 / 2 1}$ patients with groin dissections. Invasion of corpora cavernosa, high histological grade, and presence of vascular/perineural invasion were more prevalent in metastatic cases. In 21 patients followed, the cancer-specific mortality rate was $33 \%$ with a mean survival time of 2.8 years. Warty-basaloid carcinomas are morphologically distinctive human papillomavirus-related penile neoplasms that, such as basaloid carcinomas, are biologically more aggressive than typical warty carcinoma from which they should be distinguished.

Modern Pathology (2010) 23, 896-904; doi:10.1038/modpathol.2010.69; published online 19 March 2010
\end{abstract}

Keywords: penile squamous cell carcinoma; warty carcinoma; basaloid carcinoma; human papillomavirus; penile intraepithelial neoplasia; prognosis

Most cancers of the penis are squamous cell carcinomas, but there is a wide spectrum of histological subtypes. ${ }^{1-3}$ About one-third of penile tumors are exophytic and papillomatous and the differential diagnosis among them may be problematic. $^{2,3}$ Exophytic verruciform tumors include

Correspondence: Dr AL Cubilla, MD, Instituto de Patología e Investigación, Martin Brizuela 325, Asuncion 1208, Paraguay. E-mail: acubilla@institutodepatologia.com.py

Received 25 October 2009; revised and accepted 15 February 2010; published online 19 March 2010 giant condylomas, verrucous, warty (condylomatous), papillary, not otherwise specified carcinomas, and the recently described carcinoma cuniculatum. These neoplasms are associated with a good prognosis. $^{2-6}$ Other subtypes of penile squamous cell carcinomas, including usual, sarcomatoid, and basaloid carcinomas, do not depict a papillomatous pattern of growth and their prognoses range from intermediate to poor. ${ }^{2,3,7-10}$ After examination of a large number of penile carcinomas, we have occasionally encountered tumors morphologically composed of an admixture of warty and basaloid 
carcinomas. The association of these special subtypes of penile carcinomas, both showing different morphological features and biological behavior, ${ }^{2-4,7}$ is not surprising considering their presumed common human papillomavirus-related pathogenesis. ${ }^{11-13}$ In a recent large survey of human papillomavirus in invasive penile tumors, warty-basaloid carcinomas were recognized as a special tumor subtype. They were among those more commonly associated with the virus. ${ }^{13}$ However, there is no adequate clinical, pathological, and outcome characterization of wartybasaloid carcinomas. In this report, we are presenting a large number of cases to describe these features.

\section{Materials and methods}

Clinical charts and pathologic materials from 45 patients were retrospectively evaluated. They were from the Pathology Department files of the Instituto de Patología e Investigación, Asuncion, Paraguay (24 cases); M.D. Anderson Cancer Center, Houston, Texas (13 cases); and Hospital do Cancer A.C. Camargo, São Paulo, Brazil (8 cases). Twentyone patients received prophylactic bilateral groin dissection.

\section{Clinicopathologic Features}

Clinical and pathological features evaluated included patient's age, tumor anatomical site, tumor maximum diameter (in $\mathrm{cm}$ ), anatomical level of invasion, tumor thickness (in mm), histological grade, proportions of warty vs basaloid component, presence of vascular and perineural invasion, associated precancerous lesions, lichen sclerosus, and outcome. Warty features included the presence of papillae lined by polygonal cells with distinctive cellular boundaries, ample eosinophilic clear cytoplasm, and more or less prominent koilocytes (cells with wrinkled hyperchromatic nuclei, perinuclear halo, and frequent bi and multinucleation). Basaloid features referred to the presence of a monotonous population of poorly differentiated cells with scant basophilic cytoplasm, indistinctive cellular borders, inconspicuous nucleoli, and high-mitotic/apoptotic rate. If a centrally necrotic tumor nest was entirely composed of eosinophilic keratinized large squamous cells, either with or without koilocytosis, it was not classified as basaloid or warty-basaloid. The minimal tissue proportion of either warty or basaloid pattern required for diagnosis was $10 \%$. Mixed tumors showing other histological features were excluded.

Tumor thickness was measured from the nonkeratinized uppermost superficial tumor cell layer to the deepest point of invasion. Histological grading was performed using previously reported criteria $^{14}$ as follows: grade 1 , tumors composed of neoplastic cells almost undistinguishable from normal epithelial cells, except for a minimal basal/ parabasal atypia; grade 2, tumors composed of neoplastic cells with more evident nuclear atypias, but with a clear tendency toward squamous maturation; grade 3, tumors composed of any proportion of anaplastic cells with nuclear pleomorphism, hyperchromasia, irregular nuclear membrane, coarse chromatin, and prominent nucleolus. All grade 3 tumors were considered high-grade tumors, whereas the designation of low-grade tumor was reserved for grades 1 or 2 neoplasms. Presence of perineural and vascular invasion was evaluable in 40 cases. Associated lesions included lichen sclerosus and penile intraepithelial neoplasia, the latter subclassified in differentiated, basaloid, warty, and wartybasaloid. ${ }^{15}$ Differentiated ('simplex') penile intraepithelial neoplasia was characterized by atypical epithelial cells, more prominent at bottom layers, with retained squamous maturation, evident intercellular bridges, acanthosis, hyperkeratosis with parakeratosis, and hypergranulosis. In basaloid penile intraepithelial neoplasia, the epithelium was replaced by a monotonous population of small basophilic cells with high nuclear/cytoplasmic ratio, indistinctive cellular borders, and high-mitotic/apoptotic rate. In warty penile intraepithelial neoplasia, the epithelium exhibited a spiky surface with parakeratosis, conspicuous koilocytosis, acanthosis, and nuclear pleomorphism. Warty-basaloid penile intraepithelial neoplasia showed the two aforementioned patterns intermingled, with basaloid cells at the bottom and warty changes in the surface. The diagnosis of lichen sclerosus required the presence of an evident subepithelial dense hyalinization band with an underlying chronic inflammatory infiltrate. ${ }^{16}$

Follow-up was available in 21 patients and ranged from 6 to 304 months (mean 85 months, median 34 months). For mortality rate estimations, only cancerspecific deaths were taken into account.

\section{Clinicopathologic Comparison with Other Squamous Cell Carcinomas Subtypes}

Comparison of clinicopathologic features of wartybasaloid and other subtypes of squamous cell carcinomas was performed using previously reported series, which included 34, 34, and 215 cases of warty, basaloid, and usual squamous cell carcinomas, respectively. ${ }^{3,4,7}$

\section{Statistical Analysis}

For comparison among different squamous cell carcinomas subtypes analyzed, the $\chi^{2}$ or the oneway ANOVA/Kruskal-Wallis tests were performed. In all cases, a two-tailed $P<0.05$ was required for statistical significance. Data were analyzed using the software GraphPad Prism version 5.0 (GraphPad Software, La Jolla, CA, USA) and Epi-Info version 3.5.1 (Centers for Disease Control and Prevention, Atlanta, GA, USA). 


\section{Results}

\section{Clinical Features}

Clinical presentation was that of a penile mass in most cases. The majority of patients were in their sixties. About two-thirds of tumors affected multiple anatomical compartments. Glans and foreskin were common anatomical locations in tumors limited to one compartment (Table 1).

\section{Pathologic Features}

The gross appearance ranged from exophytic to endophytic tumors, but the majority of cases showed a white-gray large irregular mass extending through multiple penile compartments and measuring from 2.0 to $12.0 \mathrm{~cm}$ (mean $5.5 \mathrm{~cm}$ ). Tumor cut surface was either tan-to-white solid or mixed papillomatous on the surface and solid in deeper invasive areas (Figure 1). In most cases, deeply penetrating tumor was noted in corpus spongiosum, dartos, or corpora cavernosa through tunica albuginea. Microscopically, tumors were biphasic and complex albeit distinctive, showing variable proportions of warty and basaloid components. In 36 cases $(80 \%)$, at least half of tumor mass showed basaloid features, whereas in the remainder nine cases, areas of warty carcinoma predominated. Three microscopic patterns were found: (1) the most common, observed in two-thirds of the cases, showed a typical condylomatous aspect on tumor surface and basaloid features in deep infiltrative nests (Figure 2); (2) in $15 \%$ of the cases, there was a non-papillomatous invasive nesting pattern (Figure $3 \mathrm{a}$ and $\mathrm{b}$ ) and the central portion of the nest was usually composed of necrotic material or keratin debris; ad luminal cells were maturing keratinized squamous cells with prominent parakeratosis and koilocytosis; the peripheral one-half was composed of smaller nonkeratinized basophilic cells; (3) the least frequent

Table 1 Clinicopathologic features

\begin{tabular}{lc}
\hline Age (years) & 62 (range from 37 to 91$)$ \\
Anatomical site (\%) & \\
Glans only & $9(21)$ \\
Foreskin only & $6(13)$ \\
Coronal sulcus only & $1(2)$ \\
Multiple compartments & $29(64)$ \\
Tumor size (cm) & 5.5 (range from 2.0 to 12.0) \\
& \\
Anatomical level of invasion (\%) & $3(6)$ \\
Lamina propria & $21(47)$ \\
Corpus spongiosum/dartos & $21(47)$ \\
Corpus cavernosum & 12.5 (range from 1.0 to 50.0) \\
Tumor thickness (mm) & \\
& \\
Histological grade & $5(11)$ \\
$\quad$ Grade 2 & $40(89)$ \\
Grade 3 & $17(43)$ \\
Vascular invasion (\%) & $10(25)$ \\
Perineural invasion (\%) & \\
\hline
\end{tabular}

pattern was represented by tumors with a predominant papillomatous growth. The papillae had conspicuous fibrovascular cores. Cells with basaloid features predominated, although rounded or spindle cells were also noted. An evident clear cell koilocytosis on surface was present in all of these cases (Figure 3c and d).

Depth of invasion and tumor thickness were variable, from rare superficial to deep in erectile corpora cavernosa. In three cases, the lesion was predominantly in situ with a warty-basaloid configuration and associated foci of superficial infiltration of lamina propria. About one-half of all tumors invaded corpus cavernosum and the remainders were distributed almost equally between invasion of corpus spongiosum or preputial dartos. As corresponded to mixed tumors, histological grade was often heterogeneous, the warty component usually of grade 2, and the basaloid of grade 3. Vascular invasion was noted in almost one-half and perineural invasion in one-quarter of the cases (see Table 1).

\section{Associated Lesions}

Precancerous lesions were found in 19 cases (Figure 4). These lesions appeared in the epithelium usually continuous to the invasive carcinoma and sometimes separated from the primary tumor. The most common associated lesion was basaloid penile intraepithelial neoplasia, either alone or in combination with other lesions, especially with warty penile intraepithelial neoplasia. Differentiated penile intraepithelial neoplasia was unusual, and when present, it was combined in the same specimen with basaloid penile intraepithelial neoplasia, warty penile intraepithelial neoplasia, or both. Globally, in 18 cases, the associated penile intraepithelial neoplasia showed warty and/or basaloid features (Table 2). Lichen sclerosus was present in two cases, associated with warty-basaloid or differentiated-basaloid penile intraepithelial neoplasia, one case each.

\section{Pathologic Features and Nodal Metastasis}

Inguinal nodal metastases were present in 11 of 21 patients who received groin dissections. Microscopically, the basaloid pattern predominated in metastatic nodes, often with prominent central necrosis or hyperkeratotic/parakeratotic debris. Proportion of basaloid cells adversely influenced prognosis. One tumor with $<40 \%$ of basaloid component did not show inguinal spread. Tumors with $40-80 \%$ and $>80 \%$ of basaloid features were frequently associated with groin metastasis (45 and $67 \%$ of cases, respectively). Inguinal nodal metastasis was frequent in tumors invading erectile corpora spongiosa or cavernosa. Higher histological grade was associated with increasing incidence of nodal metastasis. The majority of tumors with vascular or 

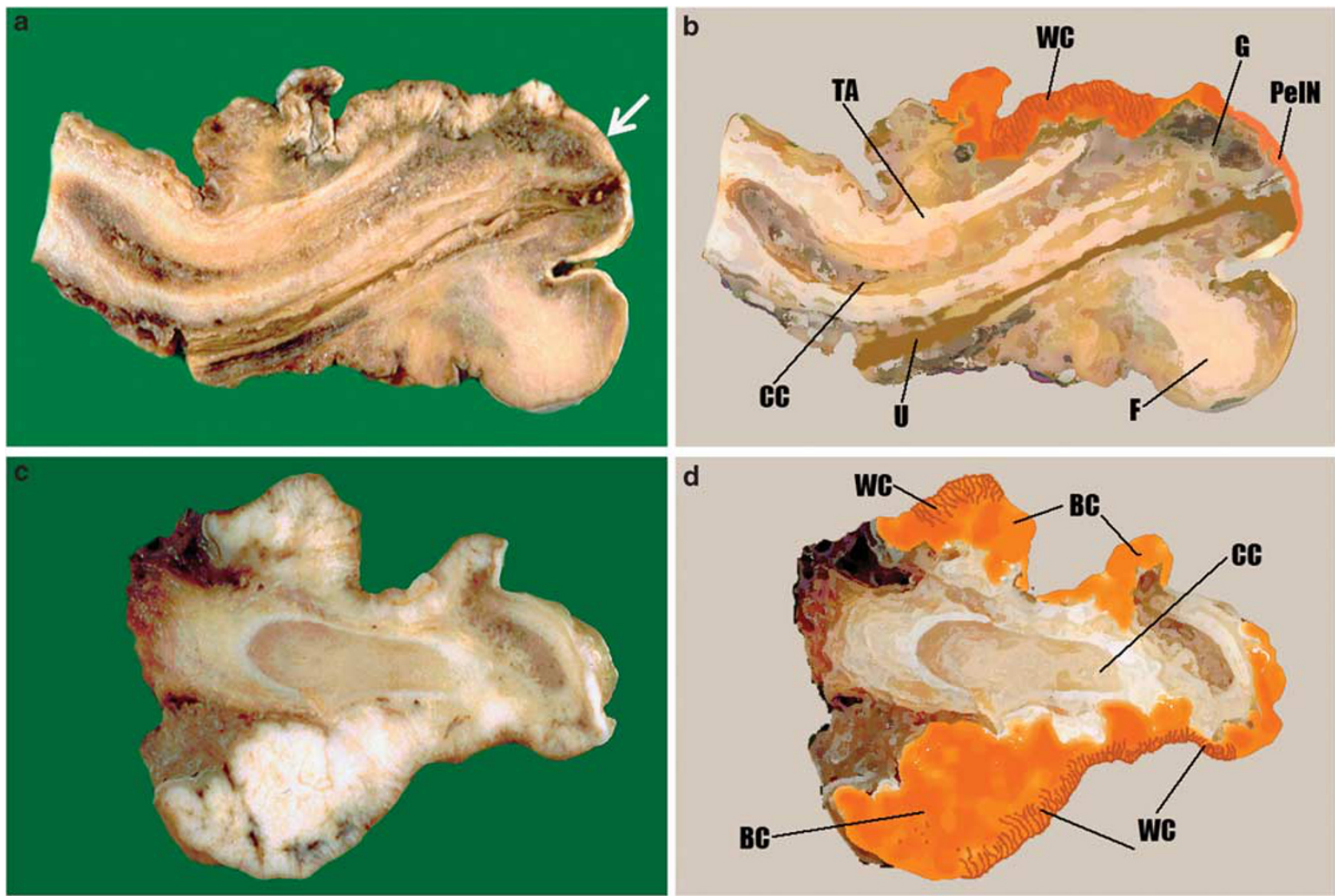

Figure 1 Gross features and diagrammatic representation of parallel sections of a warty-basaloid carcinoma. (a-d) Tumor predominantly involves dorsal and ventral foreskin (F). Glans (G) is focally compromised by a white-tan exo-endophytic tumor (in orange). The warty component (WC) is mainly superficial and papillomatous and the basaloid tumor (BC) is deeper and solid. White band-like thickening covering the glans (see arrow) histologically represents penile intraepithelial neoplasia (PeIN). Tunica albuginea (TA), erectile corpora cavernosa (CC), and utrethral tissues (U) are not involved.

perineural invasion presented groin metastasis (Table 3).

\section{Outcome Features}

Of 21 patients followed, 7 died from disseminated carcinoma (33\%), 9 died from causes unrelated to penile cancer, 1 was alive with metastatic disease at last follow-up, and 4 were alive with no evidence of disease. Most patients died within the first 3 years from diagnosis. Mean survival of patients who died from disseminated cancer was 2.8 years. The estimated survival rates at 5 and 10 years were 69 and $61 \%$, respectively.

\section{Comparison of Warty-Basaloid Carcinomas with Other Squamous Cell Carcinomas Subtypes}

Comparison of clinicopathological features and nodal status of warty-basaloid carcinomas with other subtypes of penile squamous cell carcinomas (warty, basaloid, and usual) is depicted in Table 4. Patients with warty-basaloid carcinomas were older than those with usual squamous cell carcinomas, but the difference was not significant. Wartybasaloid carcinomas most frequently originated in the foreskin than other subtypes of squamous cell carcinomas. High histological grade and tumor thickness were similar in warty-basaloid and basaloid carcinomas, whereas tumors with warty and usual features were of lower grade and thinner. The incidence of nodal metastasis in warty-basaloid tumors was similar to that of usual squamous cell carcinomas, higher than warty and lower than basaloid carcinomas.

\section{Discussion}

About $10-20 \%$ of penile squamous neoplasms are composed of variegated or mixed pathologic patterns. $^{3,17}$ Often it is problematic to classify and evaluate the prognostic significance of these mixed variants. Well known is the mixed usual-verrucous (hybrid) carcinoma with its increased risk for nodal metastasis when compared with pure verrucous carcinoma. ${ }^{9,18,19}$ Other mixed forms of penile squamous cell carcinomas have been reported as part of larger series. ${ }^{9,17}$ We are describing a hitherto poorly 

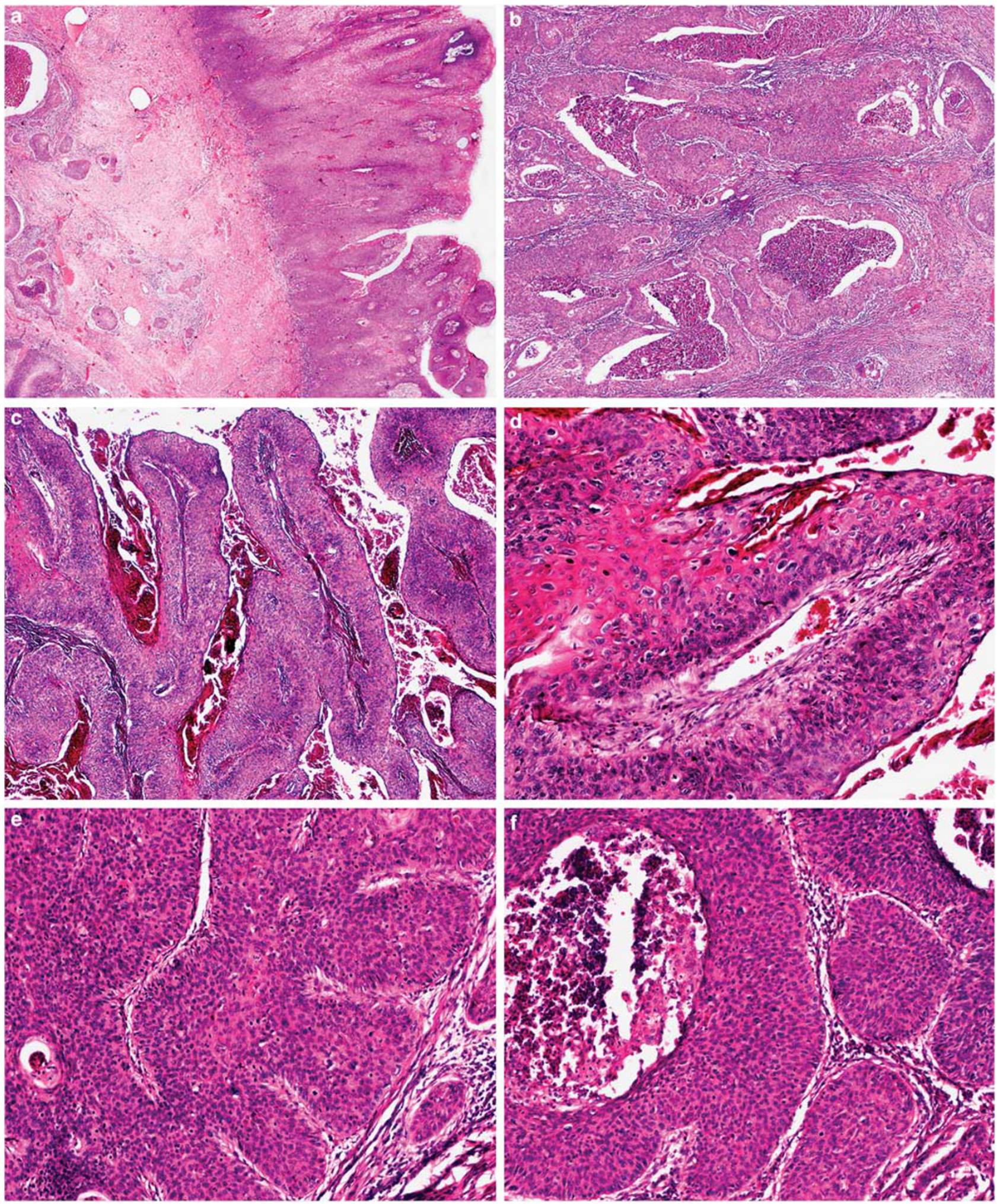

Figure 2 Microscopic features of warty-basaloid carcinoma. (a) A papillomatous superficial non-invasive warty carcinoma with condylomatous papillae harboring central fibrovascular cores (right field) and deeply infiltrating tumor nests (left field). (b) Same case showing a deeply invasive basaloid carcinoma component with comedocarcinoma-like features. (c) Low power of an exophytic papillomatous tumor with long and rounded papillae harboring prominent fibrovascular cores, which show, at higher magnification (d), the typical features of a warty carcinoma with conspicuous koilocytosis and atypical parakeratosis. The deep portion of the same tumor was composed of basaloid cells with a nesting pattern of invasion (e, f), abrupt keratinization, and evident central comedonecrosis. 

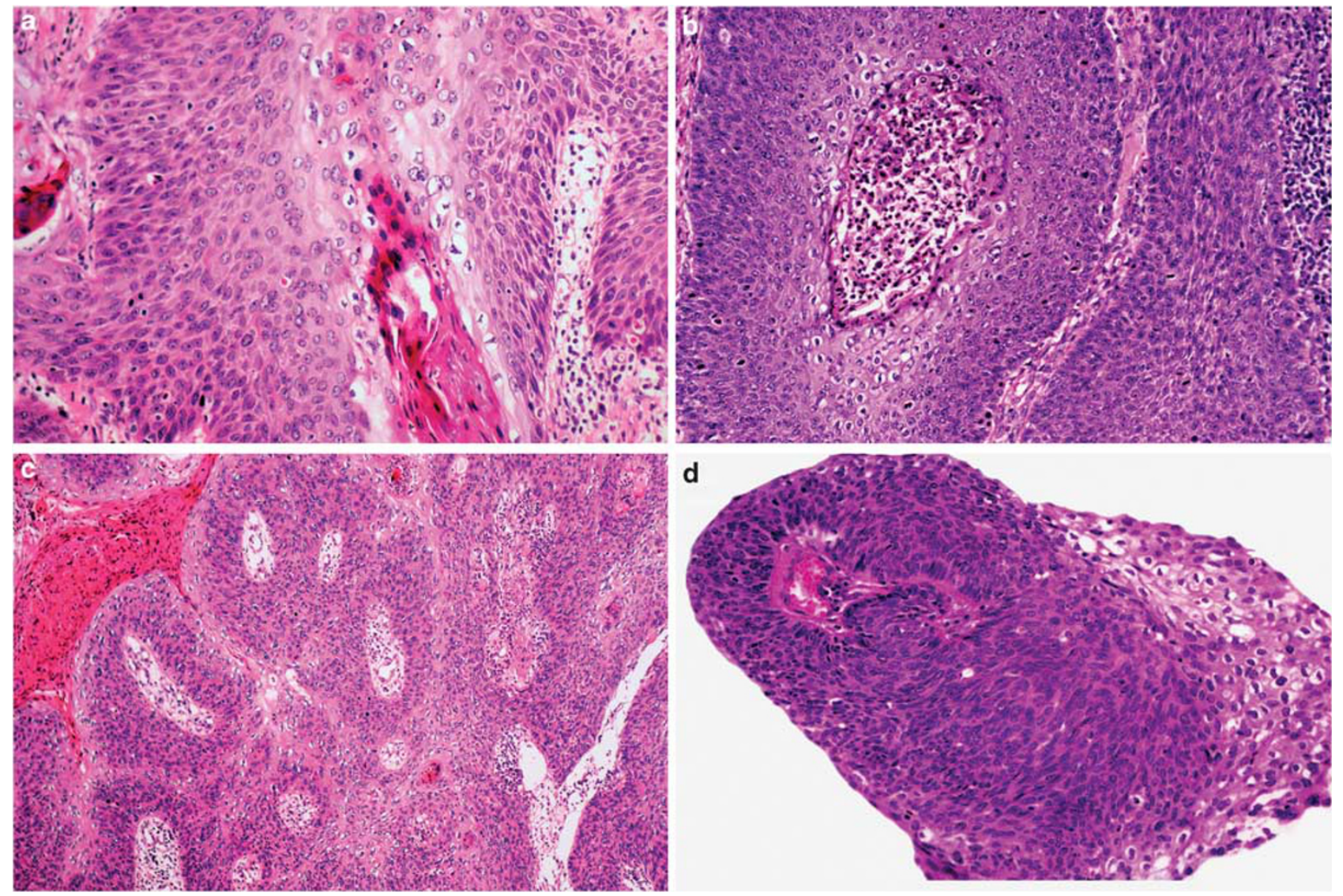

Figure 3 Microscopic features of warty-basaloid carcinoma. (a) Invasive tumor nest with central atypical parakeratosis and pleomorphic koilocytosis and peripheral small and uniform cells with basaloid features. (b) Tumor invasive nest with central necrosis composed of koilocytic clear cells and a peripheral small cell basaloid pattern. (c) Papillomatous tumor with superficial clear cell koilocytosis and central small cell basaloid features. (d) Isolated papillae with surface pleomorphic koilocytosis and predominant small and spindle basaloid cells at the center.

recognized mixed neoplasm exhibiting warty and basaloid features. Considering their common human papillomavirus-related pathogenesis and the existence of morphological mixed forms, warty and basaloid carcinomas would represent the low- and high-grade ends of a clinicopathological spectrum. In 'pure' forms, the former has an excellent prognosis, with a reported metastatic rate of $17-18 \%$ and a low cancer-specific mortality $(0-9 \%),{ }^{2-4}$ and the latter a high regional metastatic rate $(50-100 \%)$ and a mortality rate of up to $67 \%{ }^{2,3,7,20}$ Frequently, there is an overlapping of morphological features of these neoplasms, as shown in this study. Diagnostic criteria are those used for either warty or basaloid carcinomas. $^{4,7}$ Warty features include papillomatosis with papillae showing squamous maturation and koilocytosis. Basaloid features are represented by a typical nesting of tumor growth, central necrosis, abrupt keratinization and uniform undifferentiated small-to-intermediate-sized basophilic cells. In tumor nests of invasive warty carcinomas neoplastic cells are larger, with higher degrees of cell keratinization and koilocytosis. These features are not observed in the basaloid component of wartybasaloid carcinomas. The diagnosis of warty-basaloid carcinomas should be made after exclusion of pure warty or basaloid carcinomas. When in doubt about the proper allocation, the case should be classified as basaloid carcinoma as the prognosis of wartybasaloid carcinomas is considerably worse than that of warty carcinomas and, therefore, the therapeutic approach should be much aggressive.

The not too unusual association of these disparate patterns of penile carcinoma, which are biologically and morphologically distinctive, may be explained by their common association with human papillomavirus. Both warty and basaloid carcinomas have been reported as human papillomavirus-related. ${ }^{11-13}$ In a recent survey of human papillomavirus in invasive penile carcinomas, the virus was detected in 9 out of 11 tumors with warty-basaloid features $(82 \%)$ and this incidence is similar or higher to that reported for basaloid carcinoma. ${ }^{11-13}$ Human papillomavirus genotype 16 was the most common. Other genotypes involved were $6,56,59,68,73$, and 74 , the latter often combined as multiple genotypes in the same specimen. ${ }^{13}$

The distinction between a pure warty carcinoma and a warty carcinoma in which basaloid cells are observed is of clinical importance, as shown in this 


Warty-basaloid penile carcinoma
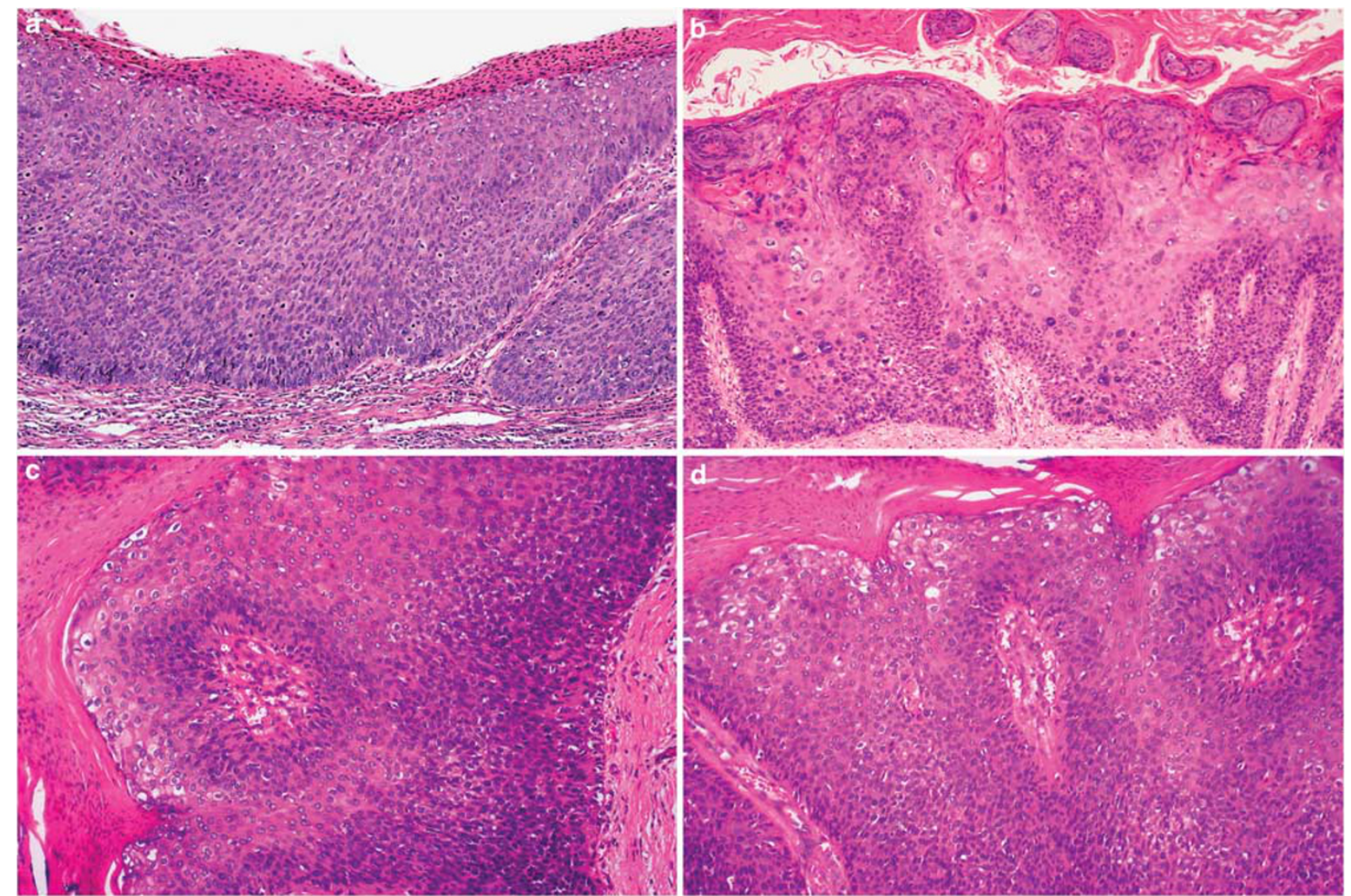

Figure 4 Penile intraepithelial neoplasia associated with warty carcinoma. (a) Basaloid penile intraepithelial neoplasia: the full thickness of the squamous epithelium is replaced by a monotonous population of small-to-intermediate size anaplastic cells with scant cytoplasm and indistinctive cell borders. A parakeratotic layer is prominent. (b) Warty penile intraepithelial neoplasia: a spiky surface with hyper and parakeratosis. There is cell maturation, koilocytosis, and marked pleomorphism. (c-d) Warty-basaloid penile intraepithelial neoplasia: there is a papillary appearance. Basaloid cells occupy the bottom half of the epithelium, whereas keratinized, eosinophilic, and more differentiated cells and koilocytes are located in the upper superficial one-half.

Table 2 Penile intraepithelial neoplasia

\begin{tabular}{ll}
\hline Subtype & No. of cases (\%) \\
\hline Basaloid & $8(42)$ \\
Warty-basaloid & $4(21)$ \\
Mixed warty-basaloid/differentiated & $6(32)$ \\
Differentiated & $1(5)$ \\
\hline
\end{tabular}

${ }^{\mathrm{a}}$ Two cases with lichen sclerosus.

study, and justifies the allocation of warty-basaloid carcinoma as a distinctive squamous cell carcinomas variant. Comparison between pure warty and warty-basaloid carcinomas disclosed a higher metastatic rate in the latter $(52 \%)$ compared with the former $(33 \%)$ and similar to that observed for usual squamous cell carcinomas (57\%). In addition, other clinical and pathological similarities and differences also emerged from this comparison, such as age at presentation, preferred anatomical site, histological grade, and tumor thickness (see Table 4). Warty-basaloid carcinomas occurred in patients older than those of warty, basaloid, and usual
Table 3 Pathological features and nodal metastasis

\begin{tabular}{lcc}
\hline Variable & \multicolumn{2}{c}{ Nodal metastasis } \\
\cline { 2 - 3 } & No. of cases & Positive (\%) \\
\hline Anatomical level & & \\
$\quad$ Lamina propria & 1 & $0(0)$ \\
Corpus spongiosum/dartos & 9 & $4(44)$ \\
$\quad$ Corpus cavernosum & 11 & $7(64)$ \\
Histological grade & & \\
$\quad$ Grade 2 & 3 & $1(33)$ \\
$\quad$ Grade 3 & 18 & $10(56)$ \\
Vascular invasion (\%) & 12 & $9(75)$ \\
Perineural invasion (\%) & 8 & $5(63)$ \\
\hline
\end{tabular}

squamous cell carcinomas and tended to originate in the inner mucosa of the foreskin, whereas the usual variant and the majority of basaloid squamous cell carcinomas preferentially originated in glans epithelium. Nearly $90 \%$ of warty-basaloid carcinomas and all basaloid carcinomas were of high grade (grade 3), whereas warty carcinomas exhibited 
Table 4 Comparison of clinicopathologic features among squamous cell carcinomas subtypes

\begin{tabular}{|c|c|c|c|c|c|}
\hline & $\begin{array}{l}\text { Warty-basaloid } \\
\text { carcinoma }\end{array}$ & $\begin{array}{c}\text { Warty } \\
\text { carcinoma }\end{array}$ & $\begin{array}{l}\text { Basaloid } \\
\text { carcinoma }\end{array}$ & $\begin{array}{l}\text { Usual squamous } \\
\text { cell carcinoma }\end{array}$ & $\mathrm{P}$-value \\
\hline Age (years) & 62 & 57 & 56 & 54 & 0.9257 \\
\hline Site $(\%)$ & & & & & $<0.0001$ \\
\hline Glans & $9(60)$ & $12(75)$ & $30(100)$ & $139(96)$ & \\
\hline Foreskin & $6(40)$ & $4(25)$ & $0(0)$ & $6(4)$ & \\
\hline Size $(\mathrm{cm})$ & 5.5 & 5.8 & 4.0 & 4.5 & 0.0900 \\
\hline Histological grade (\%) & & & & & $<0.0001$ \\
\hline Low grade & $5(11)$ & $26(76)$ & $0(0)$ & $114(53)$ & \\
\hline High grade & $40(89)$ & $8(24)$ & $34(100)$ & $101(47)$ & \\
\hline Anatomical level (\%) & & & & & 0.2096 \\
\hline Lamina propria & $3(7)$ & $2(6)$ & $1(3)$ & $6(3)$ & \\
\hline Corpus spongiosum/dartos & $21(47)$ & $15(44)$ & $8(23)$ & $96(45)$ & \\
\hline Corpus cavernosum/preputial skin & $21(46)$ & $17(50)$ & $25(74)$ & $113(52)$ & \\
\hline Thickness (mm) & 12.5 & 6.5 & 16.1 & 7.3 & $<0.0001$ \\
\hline Nodal metastasis (\%) & $11(52)$ & $6(33)$ & $17(81)$ & $60(57)$ & 0.0269 \\
\hline
\end{tabular}

high-grade areas in only one-quarter of the cases. Tumor thickness was similar in warty-basaloid and in basaloid carcinomas and significantly greater than that observed in warty and usual carcinomas. Anatomical level of maximum tumor infiltration was similar in warty and warty-basaloid carcinomas, suggesting that the latter are more aggressive neoplasms at similar tumor infiltration level than the former. Our data indicate that warty-basaloid carcinoma is a pathological entity with an intermediate prognosis between pure warty and basaloid carcinomas and a biological behavior similar to that observed in usual squamous cell carcinomas.

Taking into consideration the possible clinical implications, we recommend classifying an otherwise warty carcinoma as a warty-basaloid carcinoma if it shows $>10 \%$ of basaloid cells in the tumor mass, either in superficial papillae or in deep infiltrative nests. These basaloid cells are not a conspicuous feature of warty carcinomas, whereas they tend to predominate in warty-basaloid squamous cell carcinomas. Conversely, characteristic changes of warty carcinomas, such as papillomatosis and koilocytosis, are not found to be prominent in basaloid carcinomas, whereas they are present in warty-basaloid carcinomas in at least $10 \%$ of tumor mass. Focal koilocytosis may be present in basaloid carcinomas and focal basaloid features also may be part of an otherwise classical warty carcinoma. Tumors with these minor foci of mixed components should be classified as pure variants. The consistency of this approach is shown in the distinctive behavior of such subtypes when applying this criterion for pathological diagnosis. ${ }^{3}$

In more than one-half of cases with enough adjacent tissue for evaluation, there were foci of penile intraepithelial neoplasia, the majority of which showed basaloid or warty morphology and only rarely of differentiated type. Lichen sclerosus was unusual, and present in only two cases. The high morphologic correspondence of in situ and invasive lesions suggests that warty and basaloid penile intraepithelial neoplasia could act as precursor lesions of warty-basaloid carcinomas. The opposite occurs in usual, verrucous, and papillary, not otherwise specified invasive penile squamous cell carcinomas. In these neoplasms, there is a prevalent association with flat or verrucous squamous hyperplasia, differentiated penile intraepithelial neoplasia, and lichen sclerosus. ${ }^{15}$ The distinctive and differential distribution of associated abnormalities and precancerous lesions according to predictable subtypes of squamous cell carcinomas favors the hypothesis of a dual pathogenesis for penile cancer, one related and the other unrelated to human papillomavirus. A similar bimodal pathogenic pathway has been proposed for vulvar and anal squamous cell carcinomas. ${ }^{21,22}$ Human papillomavirus-related tumors would include warty, basaloid, and warty-basaloid carcinomas. Basaloid and warty penile intraepithelial neoplasia would be their precursor lesions. Human papillomavirus-unrelated neoplasms would correspond to usual, papillary, pseudohyperplastic, $\mathrm{cu}-$ niculatum, and sarcomatoid squamous cell carcinomas with differentiated penile intraepithelial neoplasia (simplex) as their precursor lesion. ${ }^{13}$ The latter tumors are frequently associated with squamous hyperplasia and lichen sclerosus, lesions, which are uncommonly found in warty-basaloid carcinomas.

In summary, warty-basaloid carcinomas are morphologically distinctive mixed penile neoplasms characterized by the presence of intermingled warty and basaloid features either in deep infiltrative nests or in superficial papillae. They show a higher metastatic rate than pure warty carcinomas. Distinction of warty-basaloid carcinomas from warty 
squamous cell carcinomas is of clinical importance as a more aggressive course is expected in the former when compared with the typical good prognosis of the latter.

\section{Disclosure/conflict of interest}

The authors declare no conflict of interest.

\section{References}

1 Cubilla AL, Dillner J, Schellhammer PF, et al. Tumours of the penis: malignant epithelial tumours. In: Eble JN, Sauter G, Epstein JI, Sesterhenn IA (eds). World Health Organization Classification of Tumours. Pathology \& Genetics of Tumours of the Urinary System and Male Genital Organs, First edn, Vol. 6, IARC Press: Lyon, 2004, pp 281-290.

2 Cubilla AL, Reuter VE, Velazquez E, et al. Histologic classification of penile carcinoma and its relation to outcome in 61 patients with primary resection. Int J Surg Pathol 2001;9:111-120.

3 Guimaraes GC, Cunha IW, Soares FA, et al. Penile squamous cell carcinoma clinicopathological features, nodal metastasis and outcome in 333 cases. J Urol 2009;182:528-534; discussion 34.

4 Cubilla AL, Velazques EF, Reuter VE, et al. Warty (condylomatous) squamous cell carcinoma of the penis: a report of 11 cases and proposed classification of 'verruciform' penile tumors. Am J Surg Pathol 2000;24:505-512.

5 Barreto J, Velazquez E, Ayala E, et al. Carcinoma cuniculatum: a distinctive variant of penile squamous cell carcinoma: report of 7 cases. Am J Surg Pathol 2007;31:71-75.

6 Chaux A, Soares F, Rodriguez I, et al. Papillary squamous cell carcinoma, not otherwise specified (NOS) of the penis: clinicopathologic features, differential diagnosis, and outcome of 35 cases. Am J Surg Pathol 2010;34:223-230.

7 Cubilla AL, Reuter VE, Gregoire L, et al. Basaloid squamous cell carcinoma: a distinctive human papilloma virus-related penile neoplasm: a report of 20 cases. Am J Surg Pathol 1998;22:755-761.

8 Velazquez EF, Melamed J, Barreto JE, et al. Sarcomatoid carcinoma of the penis: a clinicopathologic study of 15 cases. Am J Surg Pathol 2005;29:1152-1158.

9 Chaux A, Reuter V, Lezcano C, et al. Comparison of morphologic features and outcome of resected recurrent and nonrecurrent squamous cell carcinoma of the penis: a study of 81 cases. Am J Surg Pathol 2009;33: 1299-1306.

10 Lont A, Gallee M, Snijders P, et al. Sarcomatoid squamous cell carcinoma of the penis: a clinical and pathological study of 5 cases. J Urol 2004;172: 932-935.

11 Rubin MA, Kleter B, Zhou M, et al. Detection and typing of human papillomavirus DNA in penile carcinoma: evidence for multiple independent pathways of penile carcinogenesis. Am J Pathol 2001;159:1211-1218.

12 Gregoire L, Cubilla AL, Reuter VE, et al. Preferential association of human papillomavirus with high-grade histologic variants of penile-invasive squamous cell carcinoma. J Natl Cancer Inst 1995;87:1705-1709.

13 Cubilla AL, Lloveras B, Alejo M, et al. The basaloid cell is the best tissue marker for human papillomavirus in invasive penile squamous cell carcinoma: a study of 202 cases from Paraguay. Am J Surg Pathol 2010;34:104-114.

14 Velazquez EF, Ayala G, Liu H, et al. Histologic grade and perineural invasion are more important than tumor thickness as predictor of nodal metastasis in penile squamous cell carcinoma invading 5 to $10 \mathrm{~mm}$. Am J Surg Pathol 2008;32:974-979.

15 Chaux A, Pfannl R, Lloveras B, et al. Distinctive association of p16INK4a overexpression with penile intraepithelial neoplasia depicting warty and/or basaloid features: a study of 141 cases evaluating a new nomenclature. Am J Surg Pathol 2010;34:385-392.

16 Velazquez EF, Cubilla AL. Lichen sclerosus in 68 patients with squamous cell carcinoma of the penis: frequent atypias and correlation with special carcinoma variants suggests a precancerous role. Am J Surg Pathol 2003;27:1448-1453.

17 Chaux A, Tamboli P, Lezcano C, et al. Comparison of Subtypes of Penile Squamous Cell Carcinoma From High and Low Incidence Geographical Regions. Int J Surg Pathol 2009; Published online on 3 Jul 2009 [E-pub ahead of print]. DOI: 10.1177/ 1066896909339184

18 Kato N, Onozuka T, Yasukawa K, et al. Penile hybrid verrucous-squamous carcinoma associated with a superficial inguinal lymph node metastasis. Am J Dermatopathol 2000;22:339-343.

19 Masih AS, Stoler MH, Farrow GM, et al. Penile verrucous carcinoma: a clinicopathologic, human papillomavirus typing and flow cytometric analysis. Mod Pathol 1992;5:48-55.

20 Dai B, Ye D, Kong Y, et al. Predicting regional lymph node metastasis in Chinese patients with penile squamous cell carcinoma: the role of histopathological classification, tumor stage and depth of invasion. J Urol 2006;176:1431-1435.

21 van der Avoort IA, Shirango H, Hoevenaars BM, et al. Vulvar squamous cell carcinoma is a multifactorial disease following two separate and independent pathways. Int J Gynecol Pathol 2006;25:22-29.

22 Frisch M, Fenger C, van den Brule AJ, et al. Variants of squamous cell carcinoma of the anal canal and perianal skin and their relation to human papillomaviruses. Cancer Res 1999;59:753-757. 